\title{
Two different timing of intra uterine insemination in patients of unexplained infertility: a randomized clinical trial
}

\author{
Mervat A. Elsersy* \\ Department of Obstetrics and Gynecology, Faculty of Medicine, Alexandria University, Egypt \\ Received: 05 January 2017 \\ Accepted: 04 February 2017 \\ *Correspondence: \\ Dr. Mervat A. Elsersy, \\ E-mail: msersy@ hotmail.com \\ Copyright: (C) the author(s), publisher and licensee Medip Academy. This is an open-access article distributed under \\ the terms of the Creative Commons Attribution Non-Commercial License, which permits unrestricted non-commercial \\ use, distribution, and reproduction in any medium, provided the original work is properly cited.
}

\begin{abstract}
Background: Unexplained infertility is diagnosed when the basic infertility workup is found to be normal. The objective was to compare between the results of IUI performance at 24 hours or 36 hours after hCG injection in couples with unexplained infertility.

Methods: A prospective comparative study was conducted on 250 patients diagnosed with unexplained infertility who were randomly allocated in two equal groups. Each patient received ovulation induction. Follicular growth scanning was performed, patients received $10.000 \mathrm{hCG}$ injection when there was mature follicle equaled to or more than $18 \mathrm{~mm}$. Then they randomly allocated to either group 1 who underwent IUI 24 hours after hCG injection or group 2 who underwent IUI 36 hours after hCG injection.

Results: The positive qualitative serum $\beta$-hCG test was higher in group 1 who received IUI 24 hours after hGC injection, 24\%, while in group 2 who received IUI 36 hours after hGC injection, it was $16.8 \%$ but no statistical differences between the two studied groups could be observed. The most important finding in this study is that the clinical pregnancy rate in group 1 was significantly higher than in group 2 .

Conclusions: Earlier IUI procedures increased the clinical pregnancy rate in patients with unexplained infertility during ovulation induction with gonadotropins. Correct timing of insemination is essential.
\end{abstract}

Keywords: IUI, Ovulation induction, Randomized clinical trial, Unexplained infertility

\section{INTRODUCTION}

Unexplained infertility is diagnosed when the basic infertility workup is found to be normal. And according to the practice committee of American Society for Reproductive Medicine (ASRM), They have included ovulation assessment, hysterosalpingogram, husband semen analysis, uterine cavity assessment and if indicated tests for ovarian reserve and laparoscopy. ${ }^{1}$

The management options for unexplained infertility are various and nonspecific, because no specific defect or functional impairment is known. For example expectant treatment, ovarian stimulation with either clomiphene citrate (CC) or $\mathrm{CC}$ with gonadotropins or only gonadotropins followed by intrauterine insemination, and in vitro fertilization. ${ }^{2}$

Ovulation stimulation without IUI is not advised lately, because an analysis of the evidence concluded that 40 cycles of ovulation induction without IUI were required to achieve one extra pregnancy. ${ }^{1}$

Intrauterine insemination (IUI) is a simple and relatively less invasive and less expensive procedure than other forms of assisted reproductive technology. It entails introduction of prepared semen inside the uterine cavity directly overcoming any cervical factor and increasing the concentration of motile sperms near the fallopian tube. $^{3}$ 
The requirements for doing the procedure are: occurrence of ovulation in the IUI cycle; patent one fallopian tube at least; an adequate semen parameters for insemination; and absence of active pelvic, uterine, or cervical infection. ${ }^{4}$ In vitro fertilization (IVF) has been showed to be associated with a higher live birth. A Cochrane review by Pandian et al, concluded that IVF has higher live birth rate compared to other treatment modalities. ${ }^{5}$ Also the analysis of cost effectiveness of the various treatment options for patients with unexplained infertility showed direct proportionate relationship between the pregnancy rate/cycle and the treatment cost, but couples sometimes prefer a less expensive and less invasive option. ${ }^{5}$

In four randomized trials of patients with unexplained subfertility, pregnancy rates were better when IUI was done in stimulated cycles than in natural cycles. ${ }^{6}$ However, there are various criteria affecting the success rate of IUI including age, indications of IUI, and the sperm preparation techniques, insemination methods, and timing of insemination. ${ }^{5}$ There is no consensus on the optimal timing of IUI. In most of published studies, insemination was done 32-36 hours following human chorionic gonadotropin (hCG) administration. There was no difference in the pregnancy rate per couple in a 2014 systematic review compared the optimum time interval from hCG injection to IUI. ${ }^{4}$

Luciano et al showed that ultrasound-confirmed follicle rupture occurred on Day 1 of the luteinizing hormone (LH) surge in $6 \%$ of patients, on Day 2 in $72 \%$, and on Day 3 in $21 \% .^{8}$ In this study we are going to compare between the results of IUI performance at 24hours and 36 hours after hCG injection in couples with un explained infertility.

\section{METHODS}

It was an interventional study.

\section{Study design}

- Allocation: Randomized

- Endpoint classification: Safety/Efficacy

- Study intervention model: A 1:1 ratio by computer generated random number sequence

- Masking: Sequentially numbered sealed opaque envelopes

- $\quad$ Primary purpose: Treatment

The present prospective comparative trial was conducted in Hai Jamma hospital. The protocol was approved by institutional research committee.

\section{Eligibility}

250 women diagnosed with unexplained infertility were recruited from the outpatient clinics in Hai Jamma hospital.

\section{Inclusion criteria}

- Normal semen analysis results based on at least two semen analyses according to the World Health Organization 2010 criteria.

- Normal transvaginal ultrasound performed in the early follicular phase of cycle.

- Ovulatory midluteal serum progesterone level.

- Patency of one tubal at least, documented by hysterosalpingogram and in some cases by laparoscopy.

- Normal early follicular phase hormone assay (basal FSH, LH, estradiol (E2), prolactin (PRL), and thyroid stimulating hormone (TSH) measurements were made on Day 3 of the cycle.

\section{Exclusion criteria}

- Endometriosis

- Polycystic ovarian syndrome

- Uterine abnormality

- Poor ovarian reserve

- Male infertility

\section{Primary outcome}

Positive qualitative serum b-hCG test performed 14 days after insemination.

\section{Secondary outcome}

A clinical pregnancy. This is defined by

- the presence of a gestational sac with accompanying fetal cardiac activity by ultrasound at least 4 weeks after insemination.

- Chorionic villi identified in cases of abortion.

- Ectopic pregnancy.

\section{Enrollment}

The study was started in January 2015 and completed in December 2015.

All patients received controlled ovarian hyper stimulation which is initiated with $37.5 \mathrm{IU}$ up to $150 \mathrm{IU}$ of pure FSH or human menopausal gonadotropin (hMG) starting on Day 2 or Day 3 of the cycle. Transvaginal ultrasound had performed on Day 6 for the follicular development. A dose of $10,000 \mathrm{IU}$ urinary hCG or $250 \mathrm{mg}$ recombinant hCG was administered when at least one follicle of 18 $\mathrm{mm}$ or more was seen on transvaginal ultrasonography.

The semen was prepared using a modified Percoll gradient method. ${ }^{9}$ Two documented analyses were done before and after preparation. Women who fulfilled the criteria were inseminated with 0.5 to $1 \mathrm{ml}$ of prepared semen. 
IUI was done under trans abdominal ultrasonography guidance with full bladder using Wallace soft IUI catheter. Patient was asked to lie down in slight head low position for 30 minutes.

Patients were divided randomly into two groups at the time of hCG administration.

\section{Group 1}

125 patients will undergo IUI 24 hours after hCG administration.

\section{Group 2}

125 patients will undergo IUI 36 hours after hCG administration.

All patients are instructed to have intercourse when the dominant follicle reaches a diameter of approximately 16 $\mathrm{mm}$ and 12 hours after insemination.

Luteal phase support was in the form of micronized progesterone vaginal suppository $200 \mathrm{mg}$ twice daily for 15 days. Serum beta hCG was done on day 15 to calculate the pregnancy rate. Values above $100 \mathrm{mIU} / \mathrm{mL}$ were considered positive. Ultrasonography was done at 7 weeks to determine the clinical pregnancy rate (CPR). The demographic features, dominant follicle number, endometrial thickness on hCG day, timing of intrauterine insemination, and clinical pregnancy rates of the patients have been evaluated.
Statistical analysis was performed as follows: The continuous variables were presented as means \pm standard deviation and compared using the independent samples $\mathrm{t}$ test. The nonparametric variables and data without normal distribution were tested using the Manne Whitney $\mathrm{U}$ test, and correlation analysis was performed using Spearman's correlation test. The comparison of categorical values was made utilizing Fisher's exact test or Chi-square test. A p value $<0.05$ were considered statistically significant.

\section{RESULTS}

Analysis of data describing the demographic characteristics of patients in both groups in Table 1, showed no statistical differences between them as regards age, body mass index and infertility duration. Such findings added to the power of the analysis due to nullification of any confounding factors.

Table 1: Demographic characteristics of the patients undergoing IUI in the two studied groups.

\begin{tabular}{|llll|}
\hline & $\begin{array}{l}\text { Group 1 } \\
\text { (125) }\end{array}$ & $\begin{array}{lll}\text { Group 2 } \\
(125)\end{array}$ & p \\
\hline Age (y) & $26 \pm 9.3$ & $27 \pm 7.6$ & 0.353 \\
\hline BMI (ratio) & $23.3 \pm 3.9$ & $24 \pm 2.4$ & 0.089 \\
\hline Infertility duration (y) & $4.7 \pm 2.6$ & $4.2 \pm 3$ & 0.160 \\
\hline
\end{tabular}

Normally quantitative data was expressed in mean \pm SD and was compared using student $t$-test. $*$ Statistically significant at $p$ $\leq 0.05$.

Table 2: Cycle characteristics during follicular stimulation in the two studied groups.

\begin{tabular}{|lllc|}
\hline & Group 1(125) & Group 2 (125) & P value \\
\hline Day 3 & & & 0.069 \\
\hline FSH $(\mathrm{mIU} / \mathrm{mL})$ & $6.4 \pm 1.9$ & $6.9 \pm 2.4$ & 0.262 \\
\hline LH $(\mathrm{mIU} / \mathrm{mL})$ & $4.1 \pm 2.3$ & $3.8 \pm 1.9$ & 0.497 \\
\hline E2 $(\mathrm{pg} / \mathrm{mL})$ & $41 \pm 10.9$ & $40 \pm 12.3$ & 0.294 \\
\hline Cycle day of gonadotropin commencement $(\mathrm{d})$ & $2.2 \pm 0.8$ & $2.1 \pm 0.7$ & 0.526 \\
\hline Stimulation regiment & & & \\
\hline Receiving pure FSH & $65(52.0 \%)$ & $70(56.0 \%)$ & 0.436 \\
\hline Receiving hMG & $60(48.0 \%)$ & $55(44.0 \%)$ & 0.052 \\
\hline Sperm characters /insemination & & & 0.100 \\
\hline Sperm concentration & $35.3 \pm 12.2$ & $33.9 \pm 15.9$ & 0.190 \\
\hline Motility & $79.9 \pm 4.7$ & $81 \pm 4.2$ & \\
\hline Normal morphology & $63 \pm 4.2$ & $64 \pm 5.3$ & 0.570 \\
\hline hCG trigger day of cycle (d) & $12.2 \pm 2.8$ & $11.7 \pm 3.2$ & 0.577 \\
\hline$>$ 17 mm follicle number $(\mathbf{n})$ range & & & 0.140 \\
\hline 1-2 & $93(74.4 \%)$ & $89(71.2 \%)$ & $36(28.8 \%)$ \\
\hline 3 Or more & $32(25.6 \%)$ & $19.1 \pm 2.4$ & $8 \pm 1.7$ \\
\hline Largest diameter of leading follicle $(\mathrm{mm})$ & $18.9 \pm 3.2$ & $7.4 \pm 4.2$ & \\
\hline hCG-day endometrial thickness $(\mathrm{mm})$ & & & \\
\hline
\end{tabular}

Qualitative data were described using number and percent and was compared using Chi square test, while normally quantitative data was expressed in mean $\pm \mathrm{SD}$ and was compared using student $\mathrm{t}$-test. *: Statistically significant at $\mathrm{p} \leq 0.05$. 
Also, analysis of data describing the cycle characteristics during follicular stimulation in the two studied groups showed no significant differences, as shown in Table 2.

The positive qualitative serum $\beta$-hCG test was higher in group 1 who received IUI 24 hours after hGC injection, $24 \%$, while in group 2 who received IUI 36 hours after hGC injection, it was $16.8 \%$ but no statistical differences between the two studied groups could be observed.

The most important finding in this study is that the clinical pregnancy rate in group 1 was significantly higher than in group 2 as shown in Table 3.

Table 3: Comparison between the two studied groups as regards primary and secondary outcomes.

\begin{tabular}{|llll|}
\hline & $\begin{array}{l}\text { Group 1 } \\
(125)\end{array}$ & $\begin{array}{l}\text { Group 2 } \\
(125)\end{array}$ & $\begin{array}{l}\text { P } \\
\text { value }\end{array}$ \\
\hline $\begin{array}{l}\text { Positive } \\
\text { qualitative serum } \\
\beta \text {-hCG test }\end{array}$ & $30(24.0 \%)$ & $21(16.8 \%)$ & 0.158 \\
\hline $\begin{array}{l}\text { Clinical pregnancy } \\
\text { rate, n (\%) }\end{array}$ & $28(22.4 \%)$ & $16(12.8 \%)$ & $0.046^{*}$ \\
\hline Abortion rate, $\mathrm{n}$ & $2(1.6 \%)$ & $5(4 \%)$ & 1.000 \\
\hline
\end{tabular}

Qualitative data were described using number and percent and was compared using Chi square test. *: Statistically significant at $\mathrm{p} \leq 0.05$.

\section{DISCUSSION}

IUI with controlled ovarian hyper stimulation has been used over the years as a treatment for mild male factor, anovulation, and unexplained infertility. It is less expensive and less invasive than other assisted reproductive techniques. Therefore, these advantages have made the technique an attractive option for infertile couples. ${ }^{10}$

Age, indications of IUI, sperm preparation, and insemination methods are important factors affecting the outcome of IUI. However, the timing of IUI seemed to be the most critical factor among them. Hence, the correct timing of insemination to improve pregnancy has been the subject of controversies. ${ }^{11-14}$

The leading defect in patients with unexplained infertility is fertilization defects. This explains the importance of IUI timing, and the technique used for those patients who regularly menstruate and ovulate preceding the ovulation induction treatment cycle. ${ }^{11}$

In this study, we compared the clinical pregnancy rate of patients of unexplained infertility according to different timing of single IUI. The clinical pregnancy rate in patients in group 1 who received IUI 24 hours after hCG triggering was $22.4 \%$ while the clinical pregnancy rate in patients who received IUI 36 hours after hCG triggering was $16 \%$ which indicated favorable outcomes in group 1 .
This observation could be attributed to the sperm capacitation within the woman's genital tract. Preovulation intercourse may have improved the potentiality for fertilization and pregnancy achievement. ${ }^{15}$

Different results were observed by Huang et al who compared 210 IUIs performed at 24 hours and 36 hours, to patients with variable etiologies of infertility including endometriosis, anovulation, and unexplained infertility. The patients were divided into three subgroups who received FSH/ hMG, and clomiphene citrate (CC) /hMG. Semen parameters were normal. They concluded no significant difference in pregnancy outcomes was found between the two groups. ${ }^{16}$

Unlike the present results, Wang et al also tested the effects of different timings (24 hours and 36 hours) of IUI after hCG injection in the subgroups of patients who received clomiphene citrate, clomiphene citrate plus gonadotropin, and gonadotropin alone. The pregnancy rates were found to be similar between the two groups. ${ }^{17}$

Nearly similar results to ours were observed by Ragni et al who detected significant increases in pregnancy rates when the IUI procedure was performed during the preovulatory and periovulatory periods, but not the postovulatory period. ${ }^{18}$ The results of this study were also similar to those observed by Lin et al. ${ }^{19}$

Kucuk suggested that IUI should be withheld until follicular rupture is detected. He also claimed that monitoring of follicular rupture prior to IUI provides a pregnancy rate similar to natural fecundity. ${ }^{20}$

Blockeel et al demonstrated that significantly higher clinical pregnancy rates per IUI cycle were observed in patients undergoing IUI one day after the LH rise, when compared with patients undergoing IUI two days after the $\mathrm{LH}$ rise in natural cycles. This matches well with the results of this study. ${ }^{21}$

Yumusak et al. who evaluated the impact of intrauterine insemination timing performed 24 or $36 \mathrm{~h}$ later following ovulation trigger on clinical pregnancy rate during ovulation induction with clomiphene citrate among infertile women. They observed that IUI timing did not affect the cycle outcomes whether the procedure has been performed 24 or $36 \mathrm{~h}$ later following ovulation trigger with exogenous hCG utilization. They concluded that IUI could be done successfully at either 24 or $36 \mathrm{~h}$ after hCG in clomiphene citrate stimulated cycles. This will allow more flexibility and convenience for both physicians and patients, especially during weekends. ${ }^{22}$

\section{CONCLUSION}

Earlier IUI procedures, 24 hours from hCG injection has favorable clinical pregnancy rate in patients with unexplained infertility during ovulation induction with gonadotropins. 


\section{ACKNOWLEDGMENTS}

Authors would like to thank all the professors in the obstetrics and gynecology department for their instructions and support to complete this work.

\section{Funding: No funding sources}

Conflict of interest: None declared

Ethical approval: The study was approved by the Institutional Ethics Committee

\section{REFERENCES}

1. Practice Committee of the American Society for Reproductive Medicine. Effectiveness and treatment for unexplained infertility. Fertil Steril. Nov 2006;86(5 Suppl 1):S111-4.

2. Ganguly I, Singh A, Bhandari S, Agrawal P, Gupta N. Pregnancy predictors after intrauterine insemination in cases of unexplained infertility: a prospective study. Int J Reprod Med. 2016;2016:5817823.

3. Mackenna AI, Zegers-Hochschild F, Fernandez EO, Fabres CV, Huidobro CA, Guadarrama AR. Intrauterine insemination: critical analysis of a therapeutic procedure. Hum Reprod. 1992;7(3):3514.

4. Intrauterine insemination. Human reproduction update. 2009;15(3):265-277.

5. Matorras R, Osuna C, Exposito A, Crisol L, Pijoan JI. Recombinant FSH versus highly purified FSH in intrauterine insemination: systematic review and metaanalysis. Fertil Steril. 2011;95(6):1937-42.

6. Veltman M, Connor K, Honey M, Diener S, Bodily D. Collaborative practice through simulations in a multiuser virtual environment. Comput Inform Nurs. 2012;30(2):63-7.

7. Cantineau AE, Janssen MJ, Cohlen BJ, Allersma T. Synchronised approach for intrauterine insemination in subfertile couples. The Cochrane database of systematic reviews. 2014;(12):Cd006942.

8. Luciano AA, Peluso J, Koch EI, Maier D, Kuslis S, Davison E. Temporal relationship and reliability of the clinical, hormonal, and ultrasonographic indices of ovulation in infertile women. Obstet Gynecol. 1990;75(3 Pt 1):412-6.

9. Check JH, Zavos PM, Katsoff D, Kiefer D. Effects of Percoll discontinuous density gradients vs SpermPrep II vs Sephadex G-50 gel filtration on semen parameters. Tohoku J Experimenta Med. 1993;169(3):22531.

10. Yilmaz NK, Sargin A, Erkilinc S, Ozer I, EnginUstun Y. Does ovulation induction and intrauterine insemination affect perinatal outcomes in singletons? J Matern Fetal Neonatal Med. 2016:1-9.

11. Duran HE, Morshedi M, Kruger T, Oehninger S. Intrauterine insemination: a systematic review on determinants of success. Hum Reprod Update. 2002;8(4):373-84.

12. Khalil MR, Rasmussen PE, Erb K, Laursen SB, Rex S, Westergaard LG. Homologous intrauterine insemination. An evaluation of prognostic factors based on a review of 2473 cycles. Acta obstetricia et gynecologica Scandinavica. 2001;80(1):74-81.

13. Kamath MS, Bhave P, Aleyamma T. Predictive factors for pregnancy after intrauterine insemination: A prospective study of factors affecting outcome. J Hum Reprod Sci. 2010;3(3):129-34.

14. Demir B, Dilbaz B, Cinar O. Factors affecting pregnancy outcome of intrauterine insemination cycles in couples with favourable female characteristics. J Obstet Gynaecol. 2011;31(5):420-3.

15. Liu M. Capacitation-associated glycocomponents of mammalian sperm. Reprod Sci. 2016;23(5):572-94.

16. Huang FJ, Chang SY, Lu YJ, Kung FT, Tsai MY, $\mathrm{Wu}$ JF. Two different timings of intrauterine insemination for non-male infertility. J Assist Reprod Genet. 2000;17(4):213-17.

17. Wang YC, Chang YC, Chen IC, Cnien HH, Wu GJ. Comparison of timing of IUI in ovarian stimulated cycles. Archives Andro. 2006;52(5):371-4.

18. Ragni G, Somigliana E, Vegetti W. Timing of intrauterine insemination: where are we? Fertil Steril. 2004;82(1):25-6

19. Lin LT, Tsui KH, Wang PH. The earlier the better: When should intrauterine insemination be done? J Chin Med Assoc. 2016: (In press).

20. Kucuk T. Intrauterine insemination: is the timing correct? J Assist Reprod Genet. 2008;25(8):427-30.

21. Blockeel C, Knez J, Polyzos NP, De Vos M, Camus $\mathrm{M}$, Tournaye H. Should an intrauterine insemination with donor semen be performed 1 or 2 days after the spontaneous LH rise? A prospective RCT. Hum Reprod. 2014;29(4):697-703.

22. Yumusak $\mathrm{OH}$, Kahyaoglu S, Pekcan MK. Which is the best intrauterine insemination timing choice following exogenous hCG administration during ovulation induction by using clomiphene citrate treatment? A retrospective study. Springerplus. 2016;5(1):1307.

Cite this article as: Elsersy MA. Two different timing of intra uterine insemination in patients of unexplained infertility: a randomized clinical trial. Int J Reprod Contracept Obstet Gynecol 2017;6: 1071-5. 